\title{
Green Architecture Model: The Modern Methods of Quality Assessment in City Prototype
}

\author{
Mehdi Ghanbari1 \\ Hadi Aziziyan² \\ Hassan Hamzeli2 \\ ${ }^{1}$ Department of architecture, Maku Branch, Islamic Azad University, Maku, Iran \\ ${ }^{2}$ Researchers and Elite Club, Mahabad Branch, Islamic Azad University, Mahabad, Iran
}

\section{Doi:10.5901/mjss.2016.v7n4s1p74}

\section{Abstract}

As the trend of social and economic development of the modern world is moving forward the theory and practice of Green architecture and architects important role become more important. In this paper, green architecture and the main points Green architecture theory based on comprehensive analysis and historical rear, including its historical and modern theory and modern system of sustainable development practices is reviewed. In the world, in order to evaluate different areas newly refurbished buildings and the city's comprehensive environmental, social, economic, and groundbreaking features of the development of comprehensive quality evaluation method is to determine the most effective and advanced tools and methods of analysis. The importance of sustainable development is a comparative analysis of the basic characteristics of the construction quality assessment methods represent originated in different countries and regions, because it reveals the structure and weights of different evaluation methods of heavy impact. The article also describe through urban design, landscape architecture and architectural design volume Analysis Case Studies resolve outstanding Green architecture practices in architectural theory and methods of impact assessment.

Keywords: green architecture, characteristic methods, sustainable construction.

\section{Introduction}

Different cities can consist of different characteristics of quality of life, but some varieties are always present, because of natural, cultural, ethnic and other aspects. Urban communities, organizations and institutions are trying to improve living conditions in the city, mainly through balance and aspirations of the urban environment and its inhabitants other needs like clean and healthy and comfortably living in the city. Fight for a clean and healthy city is squired by the need for durable, long-lasting and efficient urban spaces and buildings. In this case, it is necessary to begin preliminary design and complete project, construction and maintenance of the project after the completion of all stages of the development of special skills and abilities. Point of interest is the analysis of more sustainable municipal areas and buildings of these specific methods is how it affects the architectural design practice.

\section{Green Building Development Pattern}

A fairer, healthier, and the principles of user-friendly atmosphere of the city, the main ideas have been adopted by realworld examples of projects and early urban utopia statement. E. Howard's (1898), T Garnier (1917), Le Corbusier's (1928), N. Milyutin cities and affordable housing system (Fig. 2, 1933) sample demonstrates excellent target of urban philosophers, researchers and practicing designers in the second half of the 19th century a more equitable social and economic conditions of the built environment to provide more ecological and social comfort from the beginning of the industrial revolution, until now days. In the exploration of the core principles of respect and through the design and construction of buildings Advanced inclusive urbanization and conservation of natural and cultural resources. Ecological function of these theoretical arguments, are comfortable living, contact the public health, social and economic potential of satisfaction among urban communities. All these theories seers achieve a better bionomic, social, economic and aesthetic quality goals for the city. 


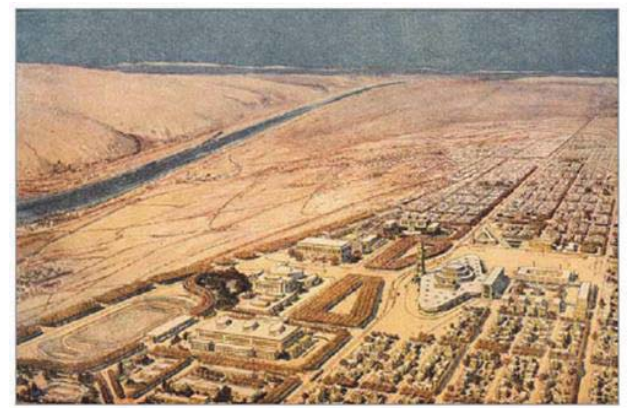

Fig. 1. Industrial City - prospect of the ideal city . 1917.

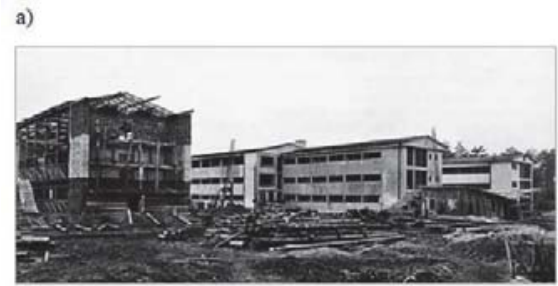

b)

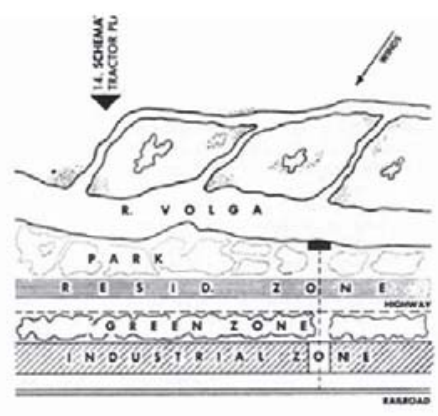

Fig. 2. Wooden structures from regional materials (a) an perfect linear urban

At the same time delineated the main principles of the driving force of modern urban guidelines, Lynch noted several layers of human values: (A) the actual value, such as housing, services, infrastructure, (B) the wishes and demands, such as higher social equality and the rational use of resources, (C) weak values, and social stability and integration, (D) concealing the values and motivations, and political control, culture, and profits and (E) the value is ignored, such as the ambient level of contact or control over the basic needs of urban ecological environment and human biology between (Lynch 1986: 53-57). In the relation to value analysis, we observed broken links or dominant and strong week and unattended to value between. Note that these values bionomics, rational use of resources, good access, and quality of the surrounding environment is determined to be the core values of urban communities dominate therefore both qualitative and quantitative aspects are very important.

The development of modern cities provide intellectual crisis syndrome researchers actively leading the city from 1960 to contact several key publications fundamental analysis. Jane Jacobs, the greatest writer of the 20th century, in her book (1961, said the city's development involves everyone, except those who live in the city - Urban Community (Jacobs Adams 1961). It evoked a positive and creative social role which is generally ignored in urban development planning. Urban land and vast public areas abandoned are nothing, but the results are not sustainable urban development and the destruction of urban policies, according to its economic disadvantaged residents of "old" housing in favor of "modern" and urban development. It was torn down in the United States and Europe, wealthy citizens. With high social interaction, while 
the history of urban communities were opened, and the newly built concrete block, never generate something similar instead.

Urban development during this period is often considered to be a crisis of urban policy both in theory and practice. Cities began to dismantle their urban neighborhoods in London, Manchester and other UK cities (Hackney 1990: 52-67) to move local residents to leave. This valuable urban architectural and social barbarism is given more affluent households goal mark. This city has become a common practice also includes former Soviet bloc countries, such as Lithuania in Europe. Brutal change destroyed many urban heritage complexes in many parts of urban communities, and caused residents to local and central authorities reflects this destructive process management of major social unrest. Many architects and members of the British royal family, and even stand up and protect the interests of society in the process of urban renovation movement, and made the relevant authorities to find a more flexible solution. Retention function and social interaction in the urban renewal process in the presence of the historic environment (1994 Jurkštas: 130-134) is especially important. As a result, participation in this event was a great architect occupational prestige, even "community architect" of a specific profession emerged. Thus, the importance of developing and maintaining the existing urban fabric of local communities has been confirmed.

Soon, in the middle of the $20^{\text {th }}$ century, as a result of pollution in large concrete blocks and the development trend of the existing highway and urban green land city and its residents, the city noise and monotonous landscape effects. Future urban and social heritage threat again, principal investigator sends a clear signal to society. First, natural design concept is evident on the basis of a careful assessment of urban design on the natural background of one of the first publicity. Growth in a metropolitan area compared to the nature and needs of living structure evolution noted the natural values of the country, region, city or the appropriate answer to a specific site, which means only the principle of bionomic urban strategy, design ( 1971: 79-83).

worldwide energy crisis in 1970 stroke progress and establishment of living, public and industrial building energy efficiency standards had intense effect in Europe and around the world. This enables national and local authorities, as well as designers and planners to review a wide range of urban development and planning policies unreasonable spacious architecture and design practice. New strategy and design prescriptions followed by densification new practice in urban areas, and a more rational and efficient architecture. Envelope thermodynamic characteristics of the building, interior space and flexible planning, application windows and a reasonable number of typical standard projects during this period (2009 Kjisik: 157-163) landmark. Copy of block housing made a massive fashion and contraction of the apartments in the space of a typical trend of Lithuania and the Soviet Union dominated the remaining space, and the principle of sustainable development and green design is unclear and undeveloped, both in theory and practice.

Planning green dimension, design and construction of the last decade has become a common trend from 20th Century. Practicing designers are more and more involved in the actual implementation of the basic idea of sustainability. Jan Gehl, green urbanization leading thinker and commentator has pointed out that the concept of "First we shape the city, and then they shape us." (Gale 2010: 9-18). Urban life is aesthetic, social, environmental and economic conditions for the formation of complex functions. Traditional local urban community on the other hand has a strong interaction and communication to make all of the city's identity engine. So that local communities can shape and maintain the ecological environment, sustainable development, good access to other aspects of the urban environment, to do it more effectively than the weaker social ties between residents .

Different quality aspects are assessed and confirmed at different levels of architectural practice, pointed out by Stauskas, renowned researchers, urban planners and architects Lithuania entertainment legend. The most important issue is the large-scale projects appropriate site selection and land available harmonious design type and architecture volume, as well as most of the buildings and surrounding landscape.

\section{Quality Evaluation Method for Urban Environment}

The actual goal of green architecture is the higher quality of the project, and there are clear bionomic, technical, economic and social advantages realized which can be measured or evaluated. Urban planning and architectural design specification requirements of the entire complex, made in the form of national technical regulations in the construction legislation. Unfortunately, in many countries, the lake of construction of this Ordinance efficiency parameters and minimum requirements of the built environment exist, so they only focus on a minimum acceptable threshold is not inspire developers, designers and contractors for the construction to go higher quality environment. This explains why the National Building Code can not be completely Green architecture goals and targets, and why you need additional tools to respond. In order to obtain certain economic, social and environmental benefits are based on the nature of the customer's 
complex objectives, specific methods and tools, resulting in benefits for these applications can not be enforced in a forced way, but only as a supplement to voluntarily Practical sustainability methodology. They can be applied on the same voluntary higher profitability, higher sales or rental price or higher commercial and professional prestige. By the combined efforts of leading researchers, businesses and public institutions, system quality assessment methods have been developed in different regions since 1990. Finally, they have integrated comprehensive quality assessment of the world's leading economic region methods: The United States, Europe and Japan. These methods have cobbled a wide road to to unify the basic principles of green building, and to implement them in green practices (Fall 2008).

Market Research Report produced by the McGraw-Hill organization in 2008 shows that in the coming decades in the global greenhouse gas effect will be the main part of the developing countries and regions, especially China, India and Southeast Asia (Global 2008 generation ). On the other hand, interaction of public, private and research twinning in the green building market will grow the most in the world - from $26 \%$ to those areas of the global project amount of $73 \%$. Therefore, Singapore and Japan in the empirical analysis of the implementation of green building policies and practices, two decades view shows that in this economic prosperity, ethnic diversity of the general trend of the regional structure and construction. On the other hand, it is far from being green, environmental protection or sustainable urban form of remarkable theoretical numerous examples appear in different Asian cities (Figure 3).

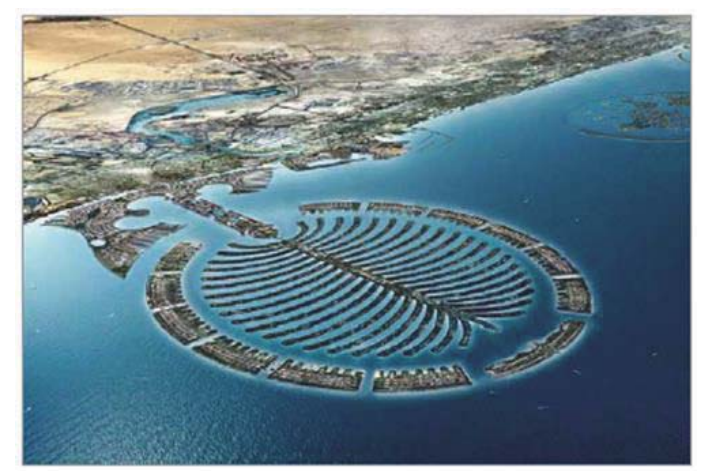

Fig. 3. Dubai Deira Island. It is a Green architecture?

Complex sustainability assessment method, the green flag, the body were more important than the market national authorities and the construction sector, in the early 1990s, in the relationship between joint decision and launch in Singapore. The system is in a particularized assessment of the small-scale eco-city environment, more large-scale buildings, social and economic quality of the tools. This system is used to introduce and establish the city as a green development of modern Singapore, a part of the activities leading concept. This aspect is just the introduction of green building principles, such as the starting position of the State of Lithuania and the neighboring Baltic countries which are particularly important. The successful implementation of green building principles and Singapore launched the key principles of a country has to move forward: (A) to implicate for public use and public funding (schools, hospitals, government buildings, etc.) of new construction and renovation of urban buildings and higher requirements; (B) the introduction to those who achieve a higher threshold for green building assessment method developer of financial and tax incentives based on recognized; (C) by participating in residential building renovations direct financing of local communities; (D) up and running architects and engineers, modern education and vocational training programs; (E) enhance the benefits of green building and other research results of public awareness through the dissemination of good practice examples; (F) the development of new and existing buildings, landscape and urban complexes (green flag in 2010) renovated high quantitative and qualitative requirements, national lawgivingand regulatory framework construction. Green flag is the tool of quality assessment of ecological, technological and social, energy efficiency, water use efficiency, environmental protection, external and internal air quality, special features, and innovation (BCA 2010). Different versions of the system allows flexible use of different functional classification of building four score threshold. This is a particularly important requirement for each common or green development, quality in line with the green flag method proofing project. As the quality of the green building sign major part is the result of a decade-long application of this method, the new construction under completion. Recently the most prestigious, the most high-sounding public projects corresponding to the highest technical and environmental requirements, the bold imagination Singapore current 
urban landscape.

BREEAM 1 is another construction quality assessment methods, widely used in Europe and beyond. Attractive contradiction BREEAM is its origin - the United Kingdom - which has been adopted in most contradictory urban development phase to begin large-scale housing and 1960- relationships and achieve national energy-saving and efficient demolition of urban communities, environmental and social development of today's architecture. This sustainable approach is to require all government-funded or co-financed the development of national legislation and building codes, for example, widely promoted British schools and hospitals, are BRE compatible. All ten areas it is a flexible and balanced approach to the assessment of similar weight (2010 BREEAM). Furthermore, BREEAM provides specific tools, indicators at the site level or heritage (Reid 2009) to measure sustainable development.

Architecture and design in the US market is clearly dominated by the LEED2 - excellent, easy to use US Green Building Council, the Association Sustainability Assessment Method which has twenty thousand participants market integration. Its reconsideration is mandatory federal and development projects in different countries, to achieve a minimum quality threshold silver. LEAD by the United States and beyond market dominance by the professional skills of sustainable land, building materials and energy, design and construction practice, interior air quality and maintenance of the specific requirements associated with the development of quality to achieve. In short this is a very clear message to the public at large through competitive quality and efficiency.

DGNB 3 method is the latest launched by Germany in 2007 to introduce this advanced tool name reveals that it is in accordance with the German Sustainable Building Council-led market participants result in Germany, Austria and Switzerland. Notable feature is a planned development evaluation in different stages of their planning from the provisional design. It can be used to check at a very early stage, when significant changes and improvements are still possible project performance. The DGNB is strongly focused on the reliability of the new buildings and the renovation and repair and maintenance of quality corresponding to the German national high-quality products and personnel. CASBEE method since 2001, is extensively applied in Japan, which is based on the demands of the built environment and building several specialized versions of the new buildings and renovation of existing assessments, urban areas and cities, in the assessment of a category the quality of elaborate user environment and loads (CASBEE2010). Quality evaluation method of the user point of intersection is a very important feature, because it opens or limit environmental projects, social, economic and aesthetic aspects of the accomplishment and ease of use. The case has a very simple user interface that allows a preliminary and final check online, in order to control costs and reduce time until improve the project. Use the correct evaluation methods in all phases of the project, it is important: After the pre-design, and design for this to provide specific tools (Fig. 4).

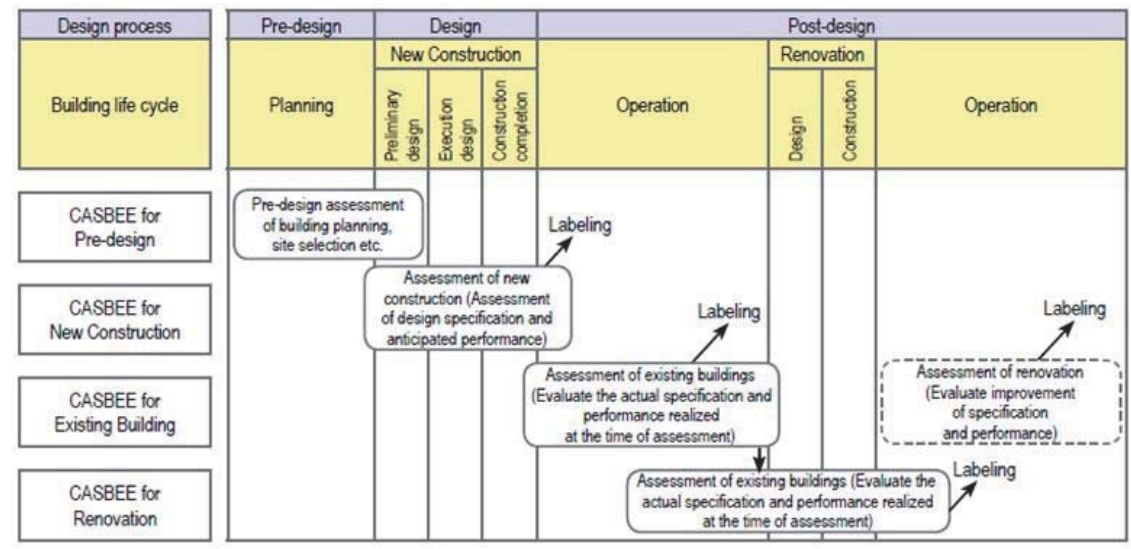

Fig. Structure 4. CASBEE method: Build a life cycle assessment of sustainable development of the four basic tools

\section{Outcome of Green Building Progress Growth in Modern Architecture}

There sustainability analysis and evaluation methods used in different parts of the world have some differences, and many common features. First, they are clearly focused on environmental, economic and human comfort and overall 
sustainable development in their new city, and the renovation of existing buildings include environmental landscape. After analyzing the different aspects of the assessment of the weight balance more differences were observed. The project is to achieve good results under BREEAM generally good estimate after LEED, while the opposite was observed dependence rarer building. This suggests that BREEAM is more stringent than the other method. Each method has its roots in each country, so it reflects the country's periphery, socio-economic and cultural realities and priorities. otherwise, all these practices of municipal strategy and architects services direct effect, which is the focus of this article.

Following , we review of approaches to sustainable development contrast analysis to reveals the different priorities of evaluation (Fig. 5). Based on the total score up to 10 - the $15 \%$ of the quality assessment method BREEAM and LEED are the strongest performance on ecological functions and allocation of building plots. Factors such projects in the planning and design process is mainly determined.

Energy efficiency of buildings and complexes is an assessment of the leading areas in that respect axis and sustainable development, but the difference is huge: from $10 \%$, to $60 \%$ of the green flag. Quality building materials influences from $9 \%$ (green flag), to $20 \%$ of the total score (BREEAM), so it is in the design process to estimate an important aspect. Sustainable water management can affect the final result from $3 \%$ to $12 \%$.

This comparison shows that, BREEAM is the most balanced approach and its impact on planning, design is the most comprehensive. Nonetheless, aspects of user involvement was omitted by the BREEAM. Analysis shows that the effect on the LEED project planning and more free design, probably because it is adjusted to a plurality of different market players and stakeholders asked the US economic environment. Version green sign by energy efficiency issues, assessment is extremely bright, but their concerns Lot features, mobility and innovation are quite small. The DGNB particularly cheered up in project management and preservation of facilities more sustainable, so other aspects receive less attention.

Different methods of sustainability is the ability of the three segments structured: (A) social aspects, such as project management, land use and regional realize innovative design and construction, the user's consciousness; (B) technical - economic aspects, such as energy efficiency, building materials and waste; (C) the environment - the site ecology, water use and pollution. These fragments are the actual urban planning and architecture, and for the ability of these matters critical details needed is the appropriate sections of sustainable development method.

Seen from a historical view, structure and content of the topic and the sustainability of different methods of analysis to put much lighter green architecture and urbanism of the required meaning. Social, technological and environmental benefits of green building and sustainable building is very obvious, and often can be seen. The fundamental role of architects and architecture in particular social, creative tools and strategies of comprehensive technical and bionomic lay into space and volume masterpiece.

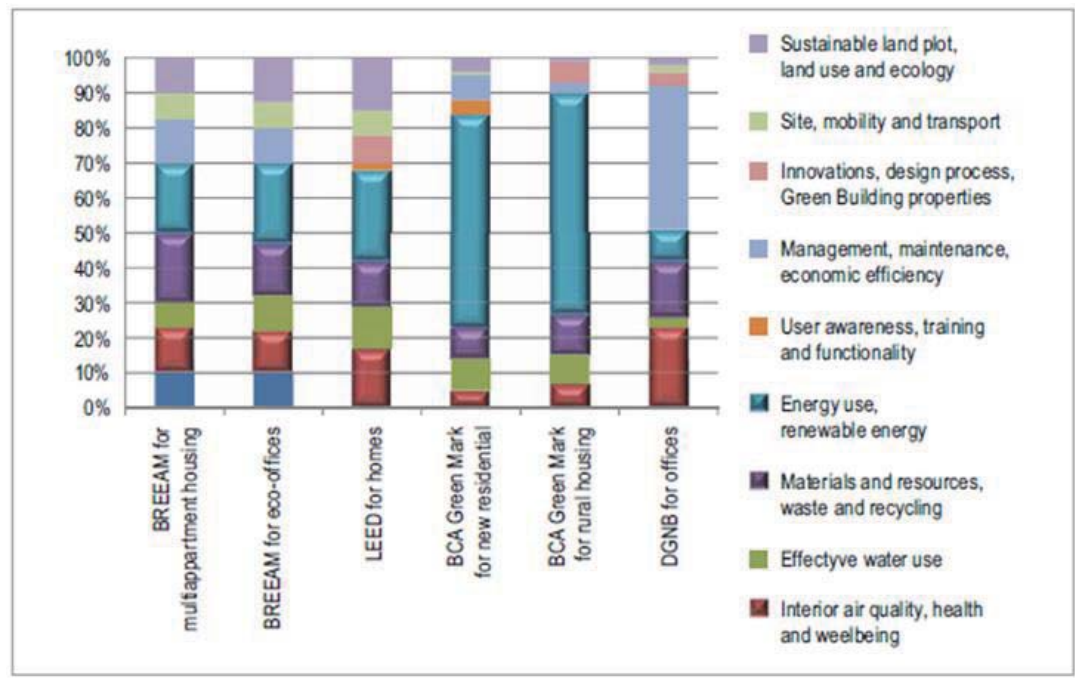

Fig. 5. Comparative analysis of the impact of different ratios of sustainable methods 
In the process of urban development, there is an initial stage in the design of a very important impact on the environment and technology. Based on the concept of Green Urban, the initial concept was based on the local natural territory value guideline , basic requirements and progress of later layer to emphasize the existing character of the territory. Aspects of sustainable development - the blue-green water management - a powerful tool for planning and landscape features of the site as the identity of the design. Sustainable regional energy system planning in which different users in an integrated energy generation and supply network (Fig. 6) functioning smart grid (or cultivating cells). At the level of planning and urban design, master - City Regional Society - the spatial and functional layout of the structural units, as well as for power generation, provision and exchange.

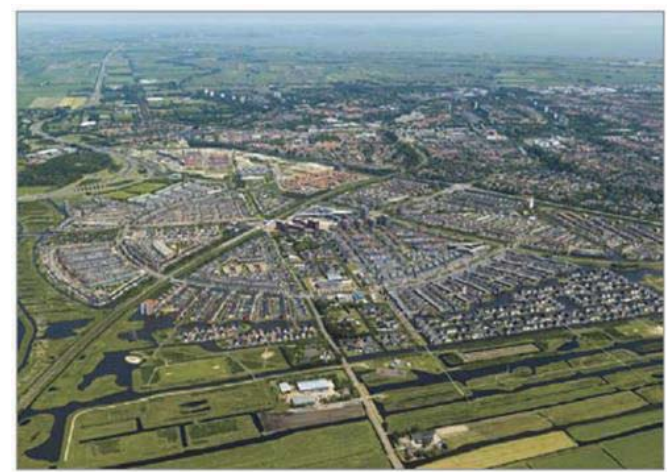

Fig. 6. Purmerrend City (the Netherlands). A living example of Slim grid energy grid. Sky Pictures

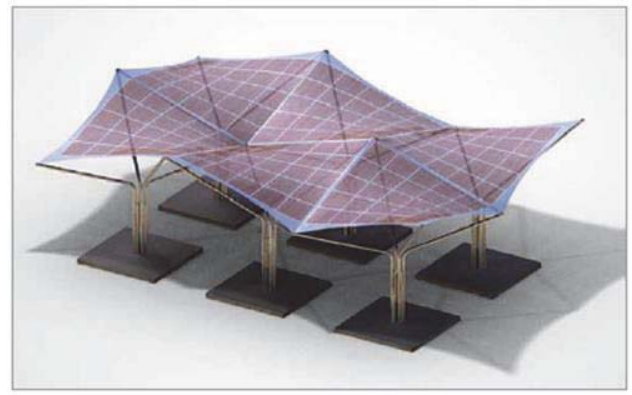

Fig. 7. The engineering design of new opportunities opening up the solar diaphragm structure and comfortable public spaces.

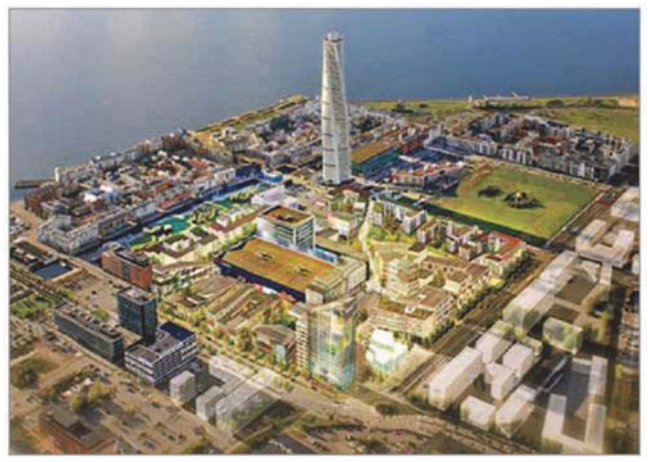

Fig. 8. Masthusen urban renewal area (Malmo, Sweden). The BREEAM certification is in progress. This versatile area 700 apartments 70,000 square meters of office space and 20,000 square meters of commercial area 
Sustainable development of individual buildings is a large-scale urban design enlarged, so it is based on only a small range, the same planning strategies. In review, need of professional capability is a major problem, especially the mentality of having a knowledge and understanding of the sustainable development of most current generation of practicing architects received on the built environment of a small college, especially in the practical level. Following progress is paving the way to advanced green building area through the work of all construction-related education chain stakeholders and professionals example: developers, material suppliers, designers and planners, contractors, supervisors and managers.

\section{Conclusions}

A model of green building, is modern building and the construction of a dominant trend. It first appeared Historic Track and deep philosophical roots of the ensuing results. bionomic, social understanding - building and economic task of art created favorable conditions for green building concept and practice of developed countries to flourish. The basic principles of green building in many developing regions are still in the exploration and practice, the development of new and existing urban renovation of the initial stages. This is the main impediment is the lack of qualified professionals in low-quality education and occupational training system results, and this week, public awareness of the issue. In the past five years and the construction of large fallen industrial development could be a good incentive to take a higher speed in such a manner as the old unsustainable projects and products no longer need the real estate market, on the one hand, and green construction gives a perfect quality progress, on the other.

Lies wider dissemination and implementation of construction, in theory, research and professional practice experts trained in the principles of sustainable development of green building. Region began implementing green construction methods in the concept of priority, choose a crossroads incentives and general policy. Countries must also make a choice to take some of the leading sustainability assessment tools and other restrictions expertise to a single method, and developing countries in all major areas of green building expertise in sustainable development therefore broaden the professional qualifications and skills, but also open up more opportunities for urban planning and design.

Green building is a very complex subject, and the focus of attention in the academic environment is on the principal investigator. Its complexity, this interdisciplinary topic and a comprehensive assessment can and should be in a modern cluster of researchers, public agencies and business partners. Green urbanization as a multi-level approach to sustainable development which should be implemented to create and maintain sustainable urban communities, which are beneficial for their citizens and their habitat practice is an important form of society.

\section{References}

Le Bihan D. Looking into the functional architecture of the brain with diffusion MRI. Nat Rev Neurosci 2003;4:469-480.

Tseng WY, Reese TG, Weisskoff RM, Brady TJ, Wedeen VJ. Myocardial fiber shortening in humans: initial results of MR imaging. Radiology 2000;216:128-139.

Tseng WY, Wedeen VJ, Reese TG, Smith RN, Halpern EF. Diffusion tensor MRI of myocardial fibers and sheets: correspondence with visible cut-face texture. J Magn Reson Imaging 2003;17:31-42.

Wedeen VJ, Reese TG, Napadow VJ, Gilbert RJ. Demonstration of primary and secondary muscle fiber architecture of the bovine tongue by diffusion tensor magnetic resonance imaging. Biophys J 2001;80:1024-1028.

Mori S, van Zijl PC. Fiber tracking: principles and strategies-a technical review. NMR Biomed 2002;15:468-480.

Wiegell MR, Larsson HB, Wedeen VJ. Fiber crossing in human brain depicted with diffusion tensor MR imaging. Radiology 2000;217:897-903.

Stejskal E, Tanner J. Spin diffusion measurements-spin echoes in presence of a time-dependent field gradient. J Chem Phys $1965 ; 42: 288-300$.

Callaghan PT. Principles of nuclear magnetic resonance microscopy. Oxford: Clarendon Press; 1991. 494 p.

Bre'maud P. Markov chains Gibbs fields, Monte Carlo simulation, and queues. New York: Springer; 1999. 444 p.

Le Bihan D, Turner R. Intravoxel incoherent motion imaging using spin echoes. Magn Reson Med 1991;19:221-227.

Horn RA, Johnson CR. Matrix analysis. Cambridge: Cambridge University Press; 1985. XIII, 561 p.

Mitra P, Halperin B. Effects of finite gradient-pulse widths in pulsed-fieldgradient diffusion measurements. J Magn Reson Ser A 1995;113:94-101.

Reese TG, Heid O, Weisskoff RM, Wedeen VJ. Reduction of eddycurrent- induced distortion in diffusion MRI using a twice-refocused spin echo. Magn Reson Med 2003;49:177-182.

Cory D, Garroway A. Measurements of translational displacement probabilities by nmr-an indicator of compartmentation. Magn Reson Med 1990;14:435-444.

Le Bihan D. Diffusion and perfusion magnetic resonance imaging: applications to functional MRI. Philadelphia: Lippincott Williams \& 
Wilkins; 1995.

Liu C, Bammer R, Acar B, Moseley M. Characterizing non-Gaussian diffusion by using generalized diffusion tensors. Magn Reson Med 2004;51:924-937.

Cohen Y, Assaf Y. High b-value q-space analyzed diffusion-weighted MRS and MRI in neuronal tissues-a technical review. NMR Biomed 2002;15:516-542.

Beaulieu C. The basis of anisotropic water diffusion in the nervous system-a technical review. NMR Biomed 2002;15:435-455.

Lin CP, Wedeen VJ, Chen JH, Yao C, Tseng WY. Validation of diffusion spectrum magnetic resonance imaging with manganeseenhanced rat optic tracts and ex vivo phantoms. Neuroimage 2003:19:482-495.

Meca C, Chabert S, Le Bihan D. Diffusion MRI at large b values: what's the limit? In: Proceedings of the 12th Annual Meeting of ISMRM, Kyoto, Japan, 2004. p 1196.

Resnick SI. A probability path. Boston/Basel: Birkhauser; 1999. XII, 453 p.

Le Bihan D. Molecular diffusion nuclear magnetic resonance imaging. Magn Reson Q 1991;7:1-30.

Chabert S, Meca C, Le Bihan D. Relevance of the information about the diffusion distribution in vivo given by kurtosis in q-space imaging. In: Proceedings of the 12th Annual Meeting of ISMRM, Kyoto, Japan, 2004. p 1238.

Mardia KV, Kent JT, Bibby JM. Multivariate analysis. London: Academic Press; 1979. XV, 521 p.

Tuch DS, Reese TG, Wiegell MR, Makris N, Belliveau JW, Wedeen VJ. High angular resolution diffusion imaging reveals intravoxel white matter fiber heterogeneity. Magn Reson Med 2002;48:577-582.

Jansons K, Alexander D. Persistent angular structure: new insights from diffusion MRI data. Dummy version. Lect Notes Comput Sci 2003;2732: 672-683.

Tuch DS, Reese TG, Wiegell MR, Wedeen VJ. Diffusion MRI of complex neural architecture. Neuron 2003;40:885-895.

Avram L, Assaf $Y$, Cohen $Y$. The effect of rotational angle and experimental parameters on the diffraction patterns and micro-structural information obtained from q-space diffusion NMR: implication for diffusion in white matter fibers. J Magn Reson 2004;169:30-38.

Caprihan A, Wang L, Fukushima E. A multiple-narrow-pulse approximation for restricted diffusion in a time-varying field gradient. J Magn Reson Ser A 1996;118:94-102. 